\title{
Transnasal endoscopic evaluation of swallowing: A bedside technique to evaluate ability to swallow pureed diets in elderly patients with dysphagia
}

\author{
Torao Sakamoto ${ }^{1}$, Akira Horiuchi MD², Yoshiko Nakayama MD²
}

T Sakamoto, A Horiuchi, Y Nakayama. Transnasal endoscopic evaluation of swallowing: A bedside technique to evaluate ability to swallow pureed diets in elderly patients with dysphagia. Can J Gastroenterol 2013;27(8):459-462.

BACKGROUND: Endoscopic evaluation of swallowing (EES) is not commonly used by gastroenterologists to evaluate swallowing in patients with dysphagia.

OBJECTIVE: To use transnasal endoscopy to identify factors predicting successful or failed swallowing of pureed foods in elderly patients with dysphagia.

METHODS: EES of pureed foods was performed by a gastroenterologist using a small-calibre transnasal endoscope. Factors related to successful versus unsuccessful swallowing of pureed foods were analyzed with regard to age, comorbid diseases, swallowing activity, saliva pooling, vallecular residues, pharyngeal residues and airway penetration/ aspiration. Unsuccessful swallowing was defined in patients who could not eat pureed foods at bedside during hospitalization. Logistic regression analysis was used to identify independent predictors of swallowing of pureed foods.

RESULTS: During a six-year period, 458 consecutive patients (mean age 80 years [range 39 to 97 years]) were considered for the study, including 285 (62\%) men. Saliva pooling, vallecular residues, pharyngeal residues and penetration/aspiration were found in 240 (52\%), 73 (16\%), $226(49 \%)$ and 232 patients (51\%), respectively. Overall, 247 patients (54\%) failed to swallow pureed foods. Multivariate logistic regression analysis demonstrated that the presence of pharyngeal residues (OR 6.0) and saliva pooling (OR 4.6) occurred significantly more frequently in patients who failed to swallow pureed foods.

CONCLUSIONS: Pharyngeal residues and saliva pooling predicted impaired swallowing of pureed foods. Transnasal EES performed by a gastroenterologist provided a unique bedside method of assessing the ability to swallow pureed foods in elderly patients with dysphagia.

Key Words: Endoscopy; Dysphagia; Swallowing
Une évaluation endoscopique transnasale de la déglutition : une technique au chevet des patients dysphagiques âgés pour évaluer la capacité à avaler un régime en purée

HISTORIQUE : Les gastroentérologues n'utilisent pas couramment l'évaluation endoscopique de la déglutition (ÉED) pour évaluer la déglutition des patients dysphagiques.

OBJECTIF : Utiliser l'endoscopie transnasale pour déterminer les facteurs prédictifs de la capacité ou non des patients dysphagiques âgés à déglutir des aliments en purée.

MÉTHODOLOGIE : Un gastroentérologue a procédé à l'ÉED d'aliments en purée au moyen d'un endoscope transnasal de petit calibre. Les chercheurs ont évalué les facteurs liés à la réussite ou à l'échec de la déglutition d'aliments en purée par rapport à l'âge, aux maladies comorbides, à l'activité de déglutition, à l'accumulation de salive, aux résidus valléculaires, aux résidus pharyngés et à la pénétration ou à l'aspiration dans les voies aériennes. L'échec de la déglutition désignait les patients qui ne pouvaient ingérer d'aliments en purée dans leur chambre pendant leur hospitalisation. L'analyse de régression logistique a permis de déterminer les prédicteurs indépendants de déglutition d'aliments en purée.

RÉSULTATS : Pendant une période de six ans, 458 patients consécutifs ont été retenus pour l'étude, dont 285 hommes (62\%) d'un âge moyen de 80 ans (plage de 39 à 97 ans). Les chercheurs ont observé une accumulation de salive, des résidus valléculaires, des résidus pharyngés et une pénétration ou une aspiration chez 240 (52\%), 73 (16\%), 226 (49\%) et 232 patients $(51 \%)$, respectivement. Dans l'ensemble, 247 patients (54\%) ne réussissaient pas à avaler les aliments en purée. L'analyse de régression logistique multivariée a démontré que la présence de résidus pharyngés (RRR 6,0) et l'accumulation de salive (RRR 4,6) se produisaient beaucoup plus souvent chez les patients dans cette situation.

CONCLUSIONS : Les résidus pharyngés et l'accumulation de salive étaient des prédicteurs d'une mauvaise déglutition des aliments en purée. L'ÉED par voie transnasale, effectuée par un gastroentérologue, était une méthode unique au chevet des patients dysphagiques âgés pour évaluer leur capacité à avaler des aliments en purée.

requirement of PEG for patients with severe dysphagia. Dysphagia patients who are able to swallow pureed foods are usually able to avoid PEG placement; therefore, evaluations that determine whether a patient can swallow pureed foods may assist the gastroenterologist in making a decision regarding the need for PEG. The aim of the present study was to identify factors influencing swallowing of pureed foods using EES performed by a gastroenterologist and a speech pathologist.

\section{METHODS}

The present analysis was a retrospective study. Inclusion criteria were patients who were admitted to Showa Inan General Hospital (Lomagane, Japan) with data recorded in the endoscopic filing system between January 2006 and December 2011. Exclusion criteria included

At our facility, a team including a gastroenterologist and a speech pathologist performs EES using a small-calibre endoscope normally used for transnasal esophagogastroduodenoscopy (EGD) to assess the

\footnotetext{
${ }^{1}$ Deparment of Rehabilitation; ${ }^{2}$ Digestive Disease Center, Showa Inan General Hospital, Komagane, Japan

Correspondence and reprints: Dr Akira Horiuchi, Digestive Disease Center, Showa Inan General Hospital, 3230 Akaho, Komagane 399-4117, Japan.

Telephone 81-265-82-2121, fax 81-265-82-2118, e-mail horiuchi.akira@sihp.jp

Received for publication March 13, 2013. Accepted May 6, 2013
} 

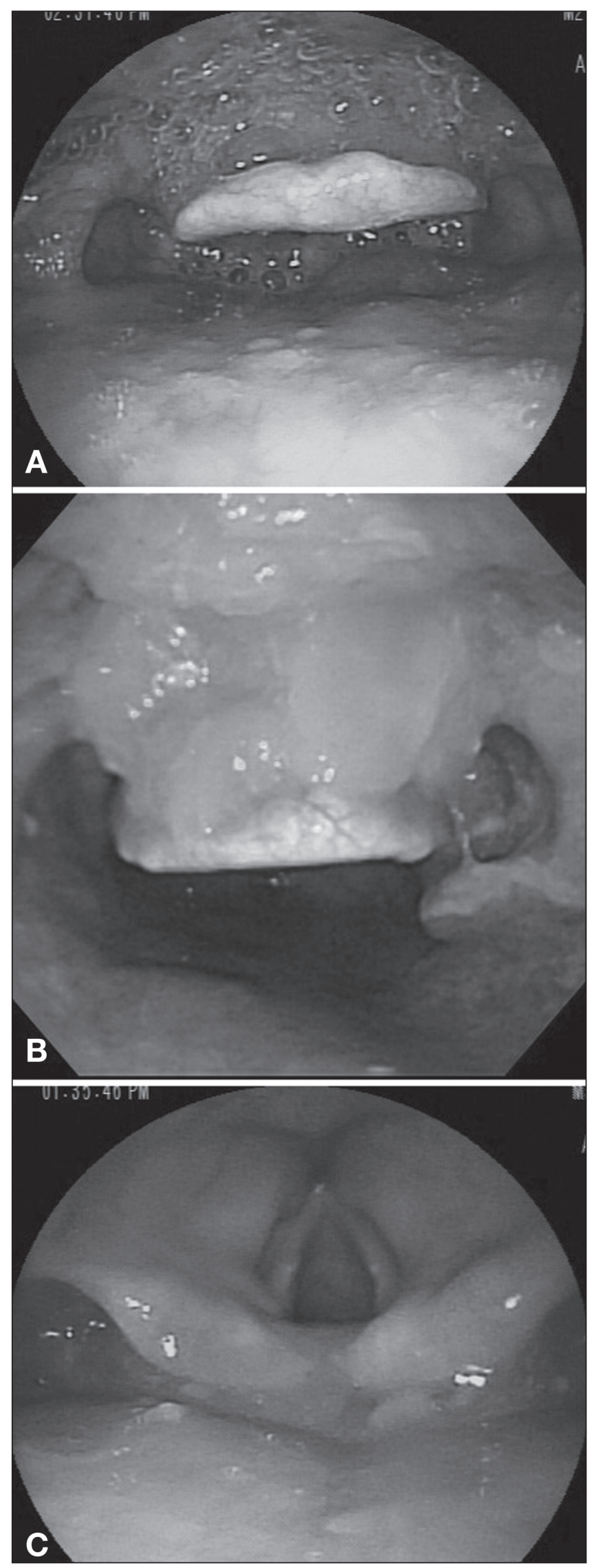

Figure 1) The findings in endoscopic evaluation of swallowing during the swallowing trial of pureed foods. A Saliva pooling. B Vallecular residues. C. Pharyngeal residues age $<20$ years, pregnancy, American Society of Anesthesiologists classification III or IV, and acute infection. A gastroenterologist, who was experienced in transnasal EGD and PEG, performed EES with a speech pathologist. There was no previous standardized training of the gastroenterologist to perform EES. The present study was approved by the Ethics Committee of Showa Inan General Hospital. Verbal and written informed consent for the procedure related to the study was obtained from all patients.

\section{Instruments}

GIF-N260 (Olympus Medical Systems, Japan) or EG530N (Fujinon Medical Systems, Japan) instruments were used for EES. These are forward-viewing upper gastrointestinal videoscopes with an ultraminiature, resolution charged-coupled device with a $120^{\circ}$ field of view, and a $5.2 \mathrm{~mm}$ or $5.9 \mathrm{~mm}$ insertion diameter and a biopsy channel of $2 \mathrm{~mm}$. The $5.2 \mathrm{~mm}$ videoscope has a tip deflection capability of 210/120 up/ down in a single plane. Other features of the $5.2 \mathrm{~mm}$ videoscope are almost the same as those of other standard videoscopes. The specifications of the $5.9 \mathrm{~mm}$ videoscope are the same as those of standard videoscopes. A digital video recorder (EVO-550H, Sony, Japan) was connected to the Olympus or Fujinon system.

\section{Procedure}

EES was performed with patients sitting at a table or sitting up in bed. Topical anesthesia of the nasal cavities was achieved using a nasal spray containing $4 \%$ lidocaine and $0.002 \%$ naphazoline solution. The small-calibre endoscope was passed transnasally, typically on the floor of the nose, to obtain a superior view of the hypopharynx. The endoscope was moved throughout the study between swallowing and postswallow positions to collect data. The swallowing position required that the distal end of the endoscope be positioned just above the top of the epiglottis so that the entire base of the tongue, tip of the epiglottis, posterior pharyngeal wall, lateral pharyngeal walls (eg, lateral channels) and laryngeal vestibule were visualized before bolus administration. The endoscope was maintained in the swallowing position throughout bolus administration and was moved only while the scope was advanced to the postswallow position following bolus presentation. To obtain the postswallow position, the distal end of the scope was advanced lower into the pharynx, past the tip of the epiglottis and into the upper portion of the laryngeal vestibule, where the glottis and trachea below could be adequately visualized; the scope was then pulled back into the swallowing position.

The endoscope was passed through the most patent nostril to view the epiglottis, pharynx and true vocal cords as patients were fed a one-teaspoon bolus of test material. Swallowing trials were performed using pureed food followed by milk. The interior larynx and airway were examined for evidence of food penetration within the laryngeal vestibule, and aspiration of food below the true vocal folds before and after each swallow. Silent aspiration, defined as lack of cough or gag reflex as the food or liquid bolus passed into the trachea, was also noted.

All patients who were analyzed were given pureed foods of the same bolus size (one teaspoon) and consistency in all procedures. For preparation of the pureed food, Toromi Perfect (Nissin Food Products Co, Ltd, Japan) was used as thickener.

\section{Evaluated measures}

Outcome measures included swallowing activity, saliva pooling in the vallecula or piriform sinuses (Figure 1A), vallecular residues (Figure 1B), pharyngeal residues (Figure 1C) and penetration/aspiration during the swallowing trial of pureed foods. After dietary recommendations were made based on the results of EES, the swallowing of diet including pureed foods was observed and assessed throughout subjects' hospitalization. Unsuccessful swallowing was defined in patients who were not able to eat pureed food at bedside.

Factors influencing swallowing of pureed foods included age, comorbid diseases, decreased swallowing activity and EES findings 
TABLE 1

Demographic and clinical data for 458 patients who underwent endoscopic evaluation of swallowing

\begin{tabular}{lc}
\hline Male sex & $285(62)$ \\
Age, years, mean (range) & $80(39-97)$ \\
Age, years & \\
$<60$ & $18(4)$ \\
$60-69$ & $34(7)$ \\
$70-79$ & $127(28)$ \\
$80-89$ & $217(47)$ \\
$\geq 90$ & $62(14)$ \\
Comorbid disease & \\
Cerebrovascular disease & $179(39)$ \\
Dementia & $120(26)$ \\
Aspiration pneumonia & $100(22)$ \\
Neuromuscular disease & $20(4)$ \\
Others & $39(9)$ \\
\hline
\end{tabular}

Data presented as $n(\%)$ unless otherwise indicated

such as saliva pooling, pharyngeal residues, vallecular residues and penetration/aspiration. All procedures were video recorded and subsequently reviewed by two gastroenterologists to assess agreement in interpretation. A standardized form was used for recording all variables. Two independent gastroenterologists assessed interpreter reliability on EES findings such as saliva pooling, pharyngeal residues, vallecular residues and penetration/aspiration. When the speech pathologist had a confounding variable for that of the gastroenterologists, the assessment of the gastroenterologists took priority over that of the speech pathologist. In addition, logistic regression analysis was applied to identify independent predictors of swallowing of pureed foods.

\section{Statistical analyses}

Interpreter reliability was assessed by calculating kappa $(\kappa)$ coefficients. The $\kappa$ statistics was used to compare the assessments of the two gastroenterologists. A $\kappa$ equal to 0 indicated no agreement between the two gastroenterologists beyond that expected by chance. A $\kappa>0.75$ was considered to have excellent reproducibility; a $\kappa$ between 0.40 and 0.75 denoted good reproducibility, and a $\kappa<0.40$ indicated poor to marginal reproducibility; $\mathrm{P}<0.05$ was considered to be indicative of statistically significant differences. Statistical analysis was performed using JMP version 9.0.2 software (SAS Institute Inc, USA).

\section{RESULTS}

Between January 2006 and December 2011, 468 patients were enrolled. Ten patients were excluded from the study because of incomplete EES results due to restlessness (6) and narrow nasal cavities (4). Finally, 458 patients who underwent EES were included in the present study. Demographic and clinical data are shown in Table 1 . There were 285 men (62\%) with a mean age of 80 years (range 39 to 97 years). Approximately $60 \%$ (279 patients) were $\geq 80$ years of age. Severe comorbid diseases, such as cerebrovascular disease (39\%), dementia (26\%) and aspiration pneumonia (22\%), were also present.

The main endoscopic findings evaluated during EES are summarized in Figure 2. Overall, all patients attempted to receive the same pureed foods. Swallowing activity was decreased in 200 (44\%). A total of 240 patients $(52 \%)$ presented with saliva pooling in the vallecula and piriform sinuses. Pureed foods were left in the vallecula $(n=73)$ and pharyngeal legion $(n=226)$. Penetration/aspiration was present in 232 patients (the mean of 243 and 220 detected by two gastroenterologists). Finally, 247 (54\%) patients failed to swallow pureed foods during hospitalization (Figure 2).

As shown in Table 2, the interobserver agreement of gastroenterologists 1 and 2 regarding saliva pooling, pharyngeal residues and vallecular residues was excellent $(\kappa=1.0)$. However, agreement regarding penetration/aspiration was poor $(\kappa=0.40)$.

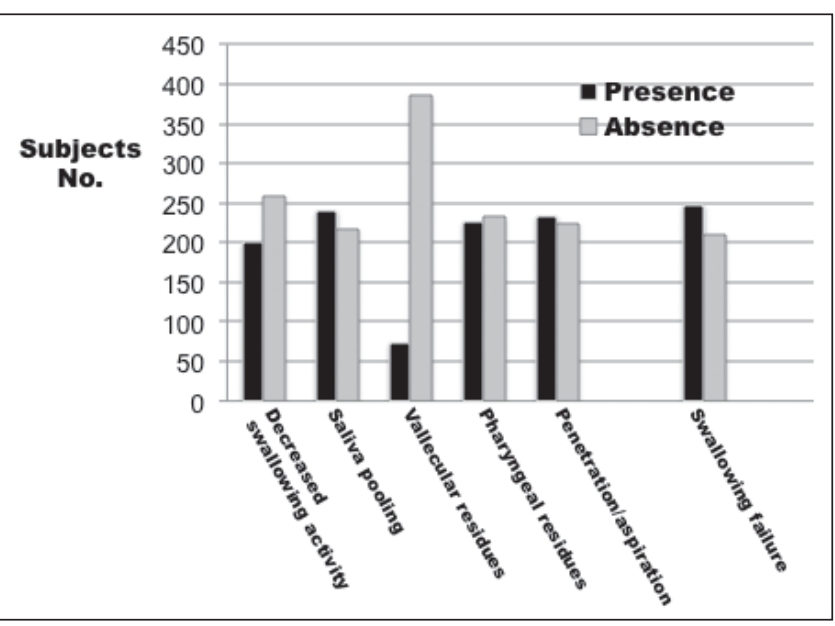

Figure 2) The presence and absence of each endoscopic evaulation of swallowing finding and failure of swallowing pureed foods when exposed to a pureed diet in 458 patients. No Number

\section{TABLE 2}

\section{Endoscopic assessments by two independent gastroenterologists in endoscopic evaluation of swallowing}

\begin{tabular}{lcc}
\hline & Gastroenterologist 1 and 2, n/n & Kappa* $^{*}$ \\
\hline Saliva pooling & $240 / 240$ & 1.0 \\
Pharyngeal residues & $226 / 226$ & 1.0 \\
Vallecular residues & $73 / 73$ & 1.0 \\
Penetration/aspiration & $243 / 220$ & 0.4 \\
\hline
\end{tabular}

*Interobserver agreement (Kappa statistics) on the presence of each endoscopic finding in endoscopic evaluation of swallowing is shown

OR of swallowing pureed food

Based on the results shown in Table 2, penetration/aspiration was eliminated from the OR analysis. As summarized in Table 3, multivariate logistic regression analysis demonstrated that pharyngeal residue (OR 6.0) and saliva pooling (OR 4.6) occurred significantly more frequently in patients who failed to swallow pureed foods. Age, presence of comorbid diseases, including cerebrovascular disease and dementia, decreased activity in swallowing and the presence of vallecular residues were not significantly associated with impaired swallowing of pureed foods.

\section{Complications}

No complications, such as cardiopulmonary events or aspiration pneumonia, occurred in the present study.

\section{DISCUSSION}

Traditionally, videofluoroscopy has been considered to be the gold standard for swallowing evaluation; however, it requires many resources including radiological equipment and trained personnel $(3,4)$. In contrast, EES can be performed at the bedside by a speech pathologist using standard fibre optic instrumentation, thus avoiding radiation exposure and possible barium aspiration encountered with videofluoroscopy $(5,6)$. Furthermore, EES is a more sensitive study and may be reliably repeated to sequentially document the resolution of swallowing disorders (5-7). However, the clinical equipment for EES is not available in many hospitals in Japan. In addition, in Japan, a speech pathologist is not permitted to perform EES alone. As a result, PEG may be performed without full and proper swallowing evaluation for elderly patients with severe dysphagia. The objectives of the present study were to analyze our experience with a unique EES, which was performed using a small-calibre endoscope passed transnasally by a gastroenterologist, and to define which factors predicted abnormal swallowing of pureed foods in patients with dysphagia. 
TABLE 3

Results of multivariate logistic regression analysis to determine variables significantly associated with difficulty in swallowing pureed food

\begin{tabular}{lcc}
\hline Variable & OR (95\% Cl) & P \\
\hline Age & $0.74(0.45-1.2)$ & 0.25 \\
Cerebrovascular disease & $1.5(0.89-2.4)$ & 0.09 \\
Dementia & $1.4(0.74-2.5)$ & 0.32 \\
Decreased swallowing activity & $1.1(0.65-1.9)$ & 0.60 \\
Saliva pooling & $4.6(2.5-8.1)$ & $<0.0001$ \\
Vallecular residues & $0.82(0.38-1.7)$ & 0.60 \\
Pharyngeal residues & $6.0(3.2-11.2)$ & $<0.0001$ \\
\hline
\end{tabular}

Although there were no a marked differences between the procedure we followed and the established EES techniques performed by a speech pathologist, the study demonstrated gastroenterologists performing the same procedure as a speech pathologist. Topical anesthesia of the nasal cavities was required for the use of a small-calibre endoscope for transnasal EGD. It is unknown whether topical anesthesia and a relatively larger endoscope would adversely affect swallowing of pureed foods.

Dysphasia diets vary considerably from facility to facility. Dysphagia diets should adjust food/liquid intake in terms of amount, consistency and timing of the meal to achieve maximal nutritional intake with minimal swallowing difficulty. Traditional oral dysphagia diets typically involve a stepwise progression of bolus consistencies. A pureed diet represents the basic level of swallowing for patients with severe dysphagia. When dysphagia patients can swallow pureed foods, they generally do not require PEG. The aim of this unique method was to assess whether the patients with severe dysphagia could swallow pureed foods. We found that patients who swallowed pureed foods without saliva pooling or pharyngeal residues during EES were able to swallow pureed foods during their hospitalization.

In the present study, two gastroenterologists independently evaluated the diagnostic accuracy of EES using a small-calibre endoscope. The results presented in Table 2 showed that it was easy for two gastroenterologists inexperienced in EES to recognize saliva pooling, pharyngeal residues and vallecular residues because each was visualized in a stationary state. However, the agreement between the gastroenterologists with regard to penetration/aspiration was poor $(\kappa=0.4)$. Generally, penetration/aspiration at any stage of EES is believed to be highly predictive of failure in swallowing food. However, even if penetration/aspiration was assessed by an experienced speech pathologist, it is difficult to properly interpret this finding (8-13). Because pharyngeal residues of pureed foods and saliva pooling appear to be a reproducible finding, we propose that they be used by gastroenterologists to assess whether patients with dysphagia can swallow pureed foods.

It is intuitive that penetration/aspiration would be a more clinically important variable in patients with swallowing dysfunction because this increases the risk of aspiration pneumonitis. This variable was excluded from analysis. The present study suggests that EES may overestimate the presence of pharyngeal residue or saliva pooling. EES may be oversensitive for these findings $(14,15)$. This raises the possibility of a high rate of false positives. If the decision to place a PEG tube is based on EES findings alone, this may result in premature or unnecessary PEG tube placement in some patients. However, pharyngeal residues of pureed foods and saliva pooling were more stable markers of impaired swallowing than penetration/aspiration in elderly patients with dysphagia because the cause of aspiration in elderly patients with dysphagia may be pharyngeal residues of food rather than direct penetration.
Our study had some limitations. First, it was retrospective in nature and comparative data with established techniques were not available. Because there was no gold standard for detection of failure to swallow, comparison with the other most commonly used method (ie, videofluoroscopic swallow study) would have provided more objective data.

\section{CONCLUSION}

Pharyngeal residues of pureed foods and saliva pooling were markers of impaired swallowing. The use of transnasal EES using these variables should be considered as a method to assess whether dysphagia patients can swallow pureed foods and to follow the course of swallowing disorders in patients with dysphagia.

ACKNOWLEDGEMENT: The authors thank David Y Graham MD and $\mathrm{Mr}$ Hiroki Komiyama for reading the manuscript and sharing their advice during its preparation.

\section{REFERENCES}

1. Rao N, Brady SL, Chaudhur IG, et al. Gold-standard? Analysis of the videofluoroscopic and fiberoptic endoscopic swallowing examinations. J Appl Res 2003;3:89-96.

2. Leder SB, Sasaki CT, Burrell MI. Fiberoptic endoscopic evaluation of dysphagia to identify silent aspiration. Dysphagia 1998:13:19-21.

3. Wu CH, Hsiao TY, Chen JC, et al. Evaluation of swallowing safety with fiberoptic endoscope: Comparison with video fluoroscopic technique. Laryngoscope 1997;107:396-401.

4. Langmore SE, Schatz K, Olson N. Endoscopic and video fluoroscopic evaluations of swallowing and aspiration. Ann Otol Rhinol Laryngol 1991;100:678-81.

5. Langmore SE, Schatz MA, Olsen N. Fiberoptic endoscopic examination of swallowing safety: A new procedure. Dysphagia 1998;2:216-9.

6. Bastian RW. The videoendoscopic swallowing study: An alternative and partner to the videofluoroscopic swallowing study. Dysphagia 1993;8:359-67.

7. Leder SB, Ross DA. Investigation of the causal relationship between tracheotomy and aspiration in the acute care setting. Laryngoscope 2000;110:641-4.

8. Rosenbek JC, Robbins JA, Roecker EB, et al. A penetrationaspiration scale. Dysphagia 1996;11:93-8.

9. Hotaling DL. Nutritional considerations for the pureed diet texture in dysphagic elderly. Dysphagia 1992;7:81-5.

10. Butler SG, Postma GN, Fischer E. Effects of viscosity, taste, and bolus volume on swallowing apnea duration of normal adults. Otolaryngol Head Neck Surg 2004;131:860-3.

11. Dziewas R, Warnecke T, Olenberg S, et al. Towards a basic endoscopic assessment of swallowing in acute stroke - development and evaluation of a simple dysphagia score. Cerebrovasc Dis 2008;26:41-7.

12. Butler SG, Stuart A, Markley L, et al. Penetration and aspiration in heal thy older adults as assessed during endoscopic evaluation of swallowing. Ann Otol Rhinol Laryngol 2009;118:190-8.

13. Butler SG, Stuart A, Kemp S. Flexible endoscopic evaluation of swallowing in healthy young and older adults. Ann Otol Rhinol Laryngol 2009;118:99-106.

14. Kelly AM, Leslie P, Beale T, et al. Fibreoptic endoscopic evaluation of swallowing and videofluoroscopy: Does examination type influence perception of pharyngeal residue severity? Clin Otolaryngol 2006;31:425-32.

15. Kelly AM, Drinnan MJ, Leslie P. Assessing penetration and aspiration: How do videofluoroscopy and fiberoptic endoscopic evaluation of swallowing compare? Laryngoscope 2007;117:1723-7. 


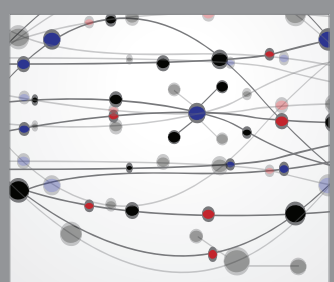

The Scientific World Journal
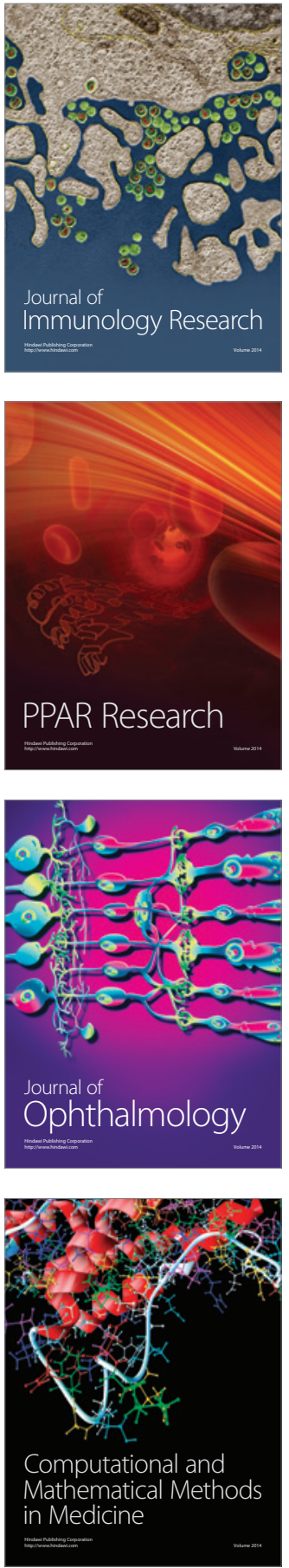

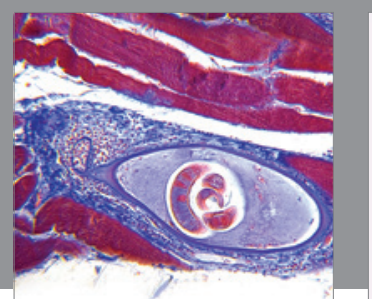

Gastroenterology Research and Practice

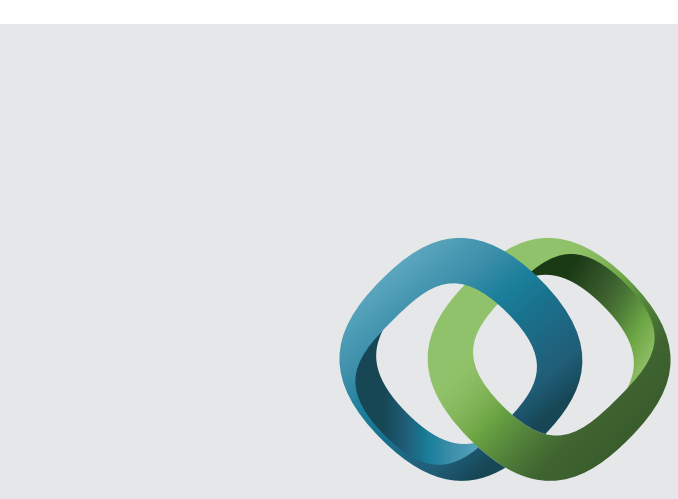

\section{Hindawi}

Submit your manuscripts at

http://www.hindawi.com
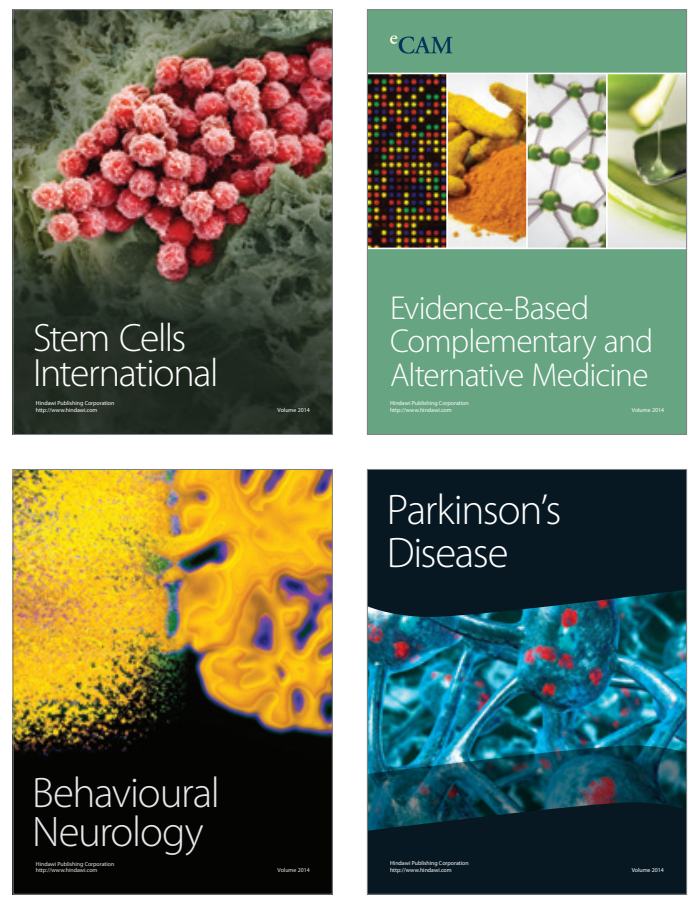
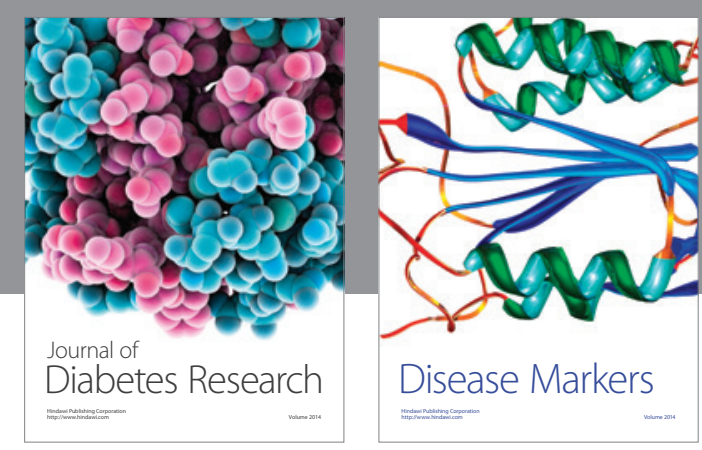

Disease Markers
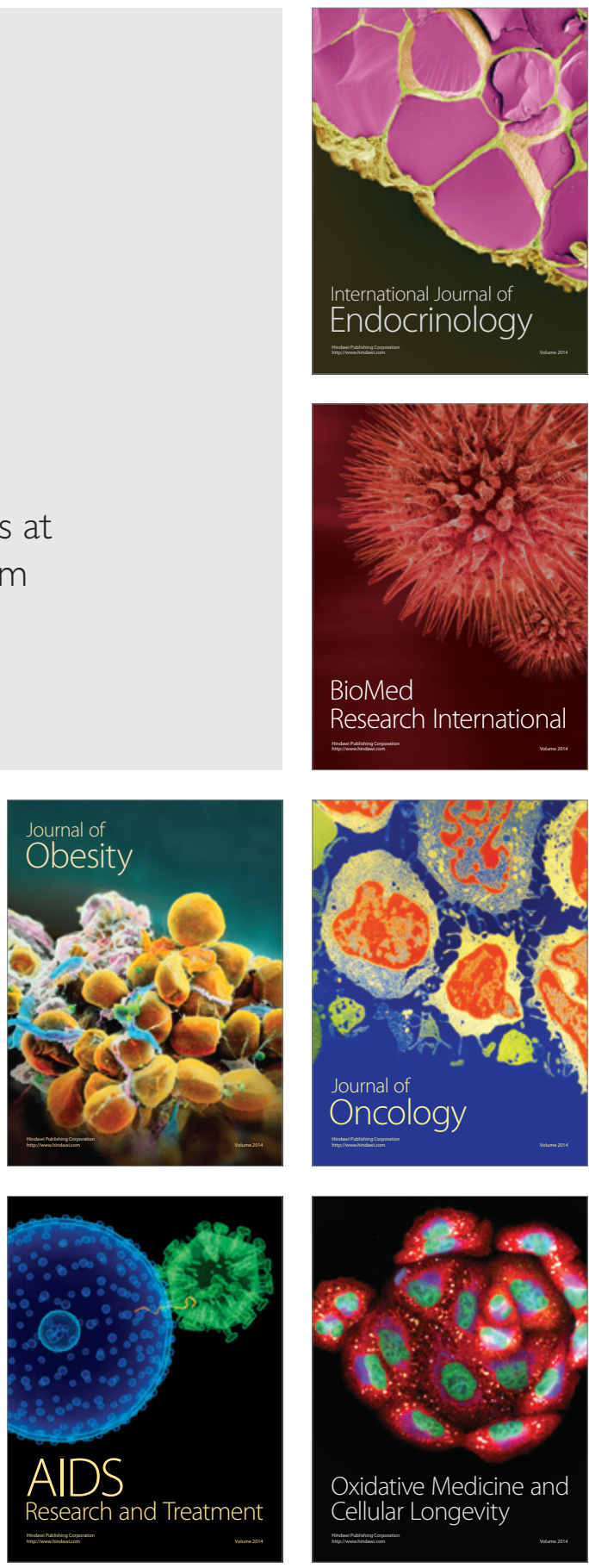